\title{
Oral Microbiome Metabarcoding in Two Invasive Small Mammals from New Zealand
}

\author{
Arsalan Emami-Khoyi 1,2,*(D), Isma Benmazouz ${ }^{3,4}$, Adrian M. Paterson ${ }^{2}$, James G. Ross ${ }^{2}$ (D), \\ Elaine C. Murphy ${ }^{2}$, Jennifer Bothwell ${ }^{2}$, Hossein Alizadeh ${ }^{5}$, Bettine Jansen van Vuuren ${ }^{1}(\mathbb{D})$ \\ and Peter R. Teske ${ }^{1}$ (D) \\ 1 Center for Ecological Genomics and Wildlife Conservation, Department of Zoology, \\ University of Johannesburg, Auckland Park 2006, South Africa; bettinevv@uj.ac.za (B.J.v.V.); \\ pteske101@gmail.com (P.R.T.) \\ 2 Department of Pest-Management and Conservation, Faculty of Agriculture and Life Sciences, \\ Lincoln University, Lincoln 7647, New Zealand; adrian.paterson@lincoln.ac.nz (A.M.P.); \\ james.ross@lincoln.ac.nz (J.G.R.); Elaine.Murphy@lincoln.ac.nz (E.C.M.); agoatingumboots@gmail.com (J.B.) \\ 3 Institute of Wildlife Conservation, SzentIstván University, 2100 Gödöllő, Hungary; betterasma@gmail.com \\ 4 Department of Nature Conservation and Wildlife Management-Institute of Medical Microbiology, \\ University of Debrecen, 4032 Debrecen, Hungary \\ 5 Bio-Protection Research Centre, Lincoln University, Lincoln 7647, New Zealand; \\ Hossein.Alizadeh@lincoln.ac.nz \\ * Correspondence: ekarsalan@gmail.com
}

Received: 1 May 2020; Accepted: 26 May 2020; Published: 10 July 2020

\begin{abstract}
All multicellular organisms host a wide diversity of microorganisms in and on their bodies, which are collectively known as their microbiome. Characterising microbial communities that inhabit different body niches in wild animals is critical to better understand the dynamics of microbiome diversityand its functional significance. The current study is the first to apply massively parallel sequencing of $16 \mathrm{~S}$ rRNA to characterise the microbial diversity and functional content of oral microbiota in two of New Zealand's most important invasive mammals, the omnivorous common brushtail possum (Trichosurus vulpecula) and the carnivorous stoat (Mustela erminea). In total, strains of bacteria belonging to 19 different phyla, 27 classes, 52 orders, 103 families, 163 genera and 51 known species were identified from the oral cavities of the study species. Strains of the phyla Proteobacteria, Firmicutes, Bacteroidetes, Fusobacteria, and Actinobacteria dominated the core oral microbial diversity in both species, while other taxa were comparatively less abundant. Despite invasive populations typically demonstrating limited genetic variation, intraspecific variation of the core bacterial taxa in the oral microbiota was considerable. This suggests that a complex interaction between genetic, physiological, and environmental factors determines the diversity of the study species'oral microbiome.
\end{abstract}

Keywords: microbiome; oral cavity; microbiota; common brushtail possum; stoat; invasive species; microbiota diversity

\section{Introduction}

Microbes have dominated Earth's evolutionary landscape for billions of years and have developed a plethora of biochemical adaptations to exploit all conceivable ecological niches on the planet. Some of these microbial metabolic repertoires ultimately became integrated into multicellular organisms [1,2], and have been an essential component in organismal evolution and development ever since [3].

All eukaryotic organisms host a variety of bacteria, archaea, fungi, protists, and viruses in and on their bodies. The combined number of these microorganisms and their genome size, known collectively 
as the microbiome, typically exceeds that of the host's somatic cells [4]. The spectrum of the relationships between eukaryote hosts and their microbial communities varies from obligate symbiosis to pathogenic dysbiosis [5,6]. Host physiology, immune systems, and genetic backgrounds influence microbiome dynamics and complexity. Similarly, microbial communities strongly affect various fitness-associated physiological functions, host development, innate and adaptive immune responses, and can even modulatehost behavior [6-14]. Evolutionary processes affect eukaryote hosts and their microbiomes concurrently $[15,16]$. Intricate and interdependent relationships between eukaryotic organisms and their microbiomes create a situation where the two evolve as a single entity, known as a holobiont [3]. This idea is the foundation of the hologenome theory of evolution [17], which maintains that eukaryotic organismal fitness is the product of the integrated activities of both the hosts and all their associated microorganisms at any given point in time. As such, holobionts and their associated hologenomes represent a previously underestimated hierarchical level of eco-evolutionary and genetic processes [18].

Compared to the microbial diversity of mammalian distal digestive tracts [19-22], the microbial diversity of the oronasal cavity has received little attention [23-30]. The oral cavity contains multiple ecological niches, such as teeth, gingival sulcus, tongue, cheeks, hard and soft palates, as well as saliva and tonsils, each of which harbours a dynamic microbial community [31,32]. Food digestion commences in the oral cavity, which serves as the first line of exposure to, and interpretation of, physio-chemical stimuli that can modulate complex feeding and mating behaviours. Pathological imbalance in the oral microbiota may progress to cardiometabolic, respiratory, immunological, gastrointestinal and obstetric diseases, with negative consequences to the host's fitness [33-36].

New Zealand was colonised by humans approximately 800 years ago [37]. Two consecutive waves of human colonisation, habitat destruction, hunting, and the introduction of alien species have had catastrophic impacts on New Zealand's endemic ecosystems [38-40]. An omnivorous marsupial, the Australian common brushtail possum (Trichosurus vulpecula), hereafter the brushtail possum, and a predatory placental mammal, the stoat (Mustela erminea), have had particularly destructive impacts. Soon after their introduction in the 1800s, these species spread rapidly in their new environments and preyed on native species that possessed no prior adaptations to evade mammalian land predators.

Moreover, brushtail possums, and to a lesser extent, stoats, form the largest reservoir of bovine tuberculosis in the wild, with potentially negative impacts on New Zealand's farming and dairy industries, as well as public health.

In 2017, New Zealand conservation and agriculture authorities started an ambitious project aimed at eradicating all invasive species from the archipelago by 2050. To reach the objectives of the "New Zealand Predator Free 2050" initiative, an in-depth understanding of the biology and natural history of the invasive species is required [41]. Characterisingthe microbial communities that live in and on the different host species is an indispensable step towards this objective.Studying the functional content of the microbiome in invasive species is of particular interest since behavioural, physiological, and genomic adaptations to new environments take place on a comparatively short evolutionary time scale, implying that evolutionary mechanisms other than those originating from the slowly-evolved host genome may be involved [12,42].

In the current study, we used metabarcoding of $16 \mathrm{~S}$ rRNA by means of massively parallel sequencing to characterise the taxonomic diversity and functional content of oral microbiota in the brushtail possum and the stoat in New Zealand and investigated the extent of intra- and inter-species variation in oral microbial diversity in the subject animals.

This study may serve as a starting point for more elaborate and robust analyses of oral microbiomes in the context of biological invasions. Such knowledge holds unprecedented therapeutic, environmental, and socio-economic promises that reach beyond the realm of wildlife genomics [43]. 


\section{Materials and Methods}

\subsection{Animal Ethics Statements}

The Lincoln University, Animal Ethics Committee approved oral sample collection and animal handling (SOP 29-14 "Protocol for sedation of possums"; SOP 33-14 "Protocol for anaesthesia of stoats"). All necessary steps were taken to minimise the pain and suffering of the test subjects.

\subsection{Sample Collection and Genomic Library Preparation}

Five adult brushtail possums (three females and two males) and five stoats (three females and two males) were live-captured from different populations on Bank Peninsula and West Coast, New Zealand. The animals were immediately transferred to the wild animal husbandry, Johnstone Memorial Laboratory at Lincoln University. After arrival at the facility, the health status of each animal was assessed by the Lincoln University wildlife veterinary team. To reduce the effects of diet on oral microbiome diversity, individuals of each species were fed the same diet prior to microbiome sample collection. The microbiome samples were collected between 9 a.m. and 12 p.m. from fasted subject animals within $36 \mathrm{~h}$ of arrival at the facility.

Stoats were anaesthetised using halothane and isoflurane inhalation protocols [44] for a maximum of $2 \mathrm{~min}$ [45], whereas the brushtail possums were lightly sedated by intravenous administration of an appropriate dosage of tiletamine-zolazepam (Zoleti ${ }^{\circledR}$ ) [46]. After complete immobilisation was achieved, each animal's outer surfaces of the gingiva in the upper and lower dental arches, the inner cheek lining, the soft and hard palates, the surface of tongue, and the floor of the mouth were carefully swabbed using a sterile cotton swab. Special attention was paid to ensuring that sample collection was consistent between individuals. The cotton swabs were air-dried in a sterile cabinet for a maximum of $5 \mathrm{~min}$, transferred to a sterile cylindrical plastic pouch, and stored at $-80^{\circ} \mathrm{C}$ until DNA was extracted, within a week.The health condition of each animal was closely monitored during and after the sampling procedure until full recovery was observed.

Metagenomic DNA of high molecular weight was extracted from the buccal swabs [47], and the hypervariable regions (V1-V2) of the $16 \mathrm{~S}$ rRNA were amplified using the primer pair 8F (5'-TCG TCG GCAGCG TCA GAT GTG TAT AAG AGA CAG AGA GTT TGA TCC TGG CTC AG-3' ) [48] and 338R (5'-GTC TCG TGG GCTCGG AGA TGT GTA TAA GAG ACA GGC TGC CTC CCG TAG GAG T-3') [49]. Primer sequences contained overhang adapters appended to the $5^{\prime}$ end for compatibility with Illumina sequencing platforms. Each PCR reaction contained $12.5 \mathrm{ng}$ of template DNA, $0.2 \mu \mathrm{M}$ of each primer and $2 \times$ KAPA HiFi HotStart Ready Mix (KAPA Biosystems, Wilmington, NC, USA). Each batch of PCR reactions included three positive and three negative control reactions. The thermal profile for PCR amplifications started with an initial denaturing step at $95^{\circ} \mathrm{C}$ for $3 \mathrm{~min}$, followed by 25 cycles of denaturing at $95{ }^{\circ} \mathrm{C}$ for $30 \mathrm{~s}$, annealing at $55^{\circ} \mathrm{C}$ for $30 \mathrm{~s}$, and a $30 \mathrm{~s}$ extension at $72{ }^{\circ} \mathrm{C}$, followed by a final 5 min extension at $72{ }^{\circ} \mathrm{C}$. PCR amplicons were purified using the AMPure XP reagent (Beckman Coulter, Indianapolis, IN, USA).This was followed by eight cycles of barcoding PCRs, each with an initial denaturing step at $95^{\circ} \mathrm{C}$ for $3 \mathrm{~min}$, annealing at $55^{\circ} \mathrm{C}$ for $30 \mathrm{~s}, 30 \mathrm{~s}$ extension at $72{ }^{\circ} \mathrm{C}$, and a final 5 min extension at $72{ }^{\circ} \mathrm{C}$. The resulting libraries were purified using the AMPure XP reagent (Beckman Coulter, Pasadena, CA, USA) and pooled in equimolar concentrations before being sequenced on an Illumina MiSeq sequencing platform (Illumina, SanDiego, CA, USA) using a V2, $2 \times 250$ bp chemistry, at the Chapel Hill Microbiome Core Facility, University of North Carolina.

Demultiplexed sequences were processed using the Qiime2 v11.2017 package [50]. Illumina sequencing adapters, contaminants, and over-represented sequences were filtered using the Qiime2 Cutadapt v1.18 plugin [51]. The Qiime2 DADA2 plugin [52] was used to remove low-quality sequences (Phred score $<25$ ), detect potential chimeric reads, and de-noise demultiplexed sequences into unique sequence features. To assign a taxonomy rank to the sequence features, the Qiime2 "blast-consensus feature classifier plugin" was used, with the number of best-accepted hits set to four, the minimum percentage identity to $70 \%$, and the $p$-value to a maximum of 0.001 . 
Quality-filtered sequences were searched against the Greengenes v13_8, 99\% OTUs full-length database [53]. Sequences that were unassigned or lacked taxonomy IDs in the NCBI taxonomy database (https://www.ncbi.nlm.nih.gov/taxonomy) were discarded. The taxonomy ID of each consensus match was extracted using an in-house Python3 script, and a circular phylogenetic tree was reconstructed using the PhyloT online server [54] and visualised in ITol v.33 [55].

To estimate the phylogenetic distance necessary for computing some diversity indices, an approximate maximum-likelihood phylogenetic tree was constructed using the package FastTree2 [56]. Before running the core diversity script in Qiime2, the sequence counts across different individuals were randomly subsampled to an estimated equal rarefaction depth of 79,690 sequences. Rarefaction at this sequencing depth resulted in the maximum number of sequences $(67.7 \%$ of the total sequences) being retained in nine individuals. To minimise the bias in diversity metrics estimation, one stoat with a lower number of sequences than the above threshold was discarded from the diversity analysis.

Four $\alpha$-diversity metrics including Faith phylogenetic distance [57], group evenness [58], Shannon diversity [59], and Bray-Curtis dissimilarity [60] were estimated separately for each species. To calculate $\beta$-diversity variation between the two species, unweighted and [61] weighted UniFrac distance [62] were computed. Principal coordinates analysis [63] was performed on a subset of diversity metrics (Bray-Curtis, Jaccard, and UniFracs), and results were visually inspected using the Emperor Python package [64].

The statistical significance for differences in $\alpha$-diversity (evenness and Faith phylogenetic indices) and $\beta$-diversity (unweighted UniFrac) between two species were tested by performing group-wise non-parametric Kruskal-Wallis [65] and permutational multivariate analysis of variance (PERMANOVA) tests [66].

To find modules of co-occurring bacterial taxa in each species, the SCNIC package (https://github.com/shafferm/SCNIC) was used to create a sparse positive co-occurrence correlation network of different bacterial taxa by setting the minimum pairwise correlation value to $0.30(R=30)$, and the network files were visualised in Gephi v0.9.2 [67].

Bacterial taxa whose abundance differed between two species were identified using the Gneiss balances method [68]. First, a correlation-clustering balance tree was constructed for each species. In the correlation-clustering algorithm, an unsupervised Ward's hierarchical clustering algorithm [69] groups different bacterial taxa interactively based on their co-occurrence in each species' oral microbiota. Then, a multivariate linear regression analysis [70] was performed independently on each node (balance) of the resulting tree and tested for significant changes in bacterial abundance between pairs of species. In the regression analysis, the description (animal ID) and taxonomic infraclass (marsupial versus placental) were selected as explanatory variables, and taxon abundance was set as the response variable. To evaluate the explanatory power of a single covariate, a leave-one-variable-out method was applied. The variable whose removal caused the most significant changes in the fitted model was reported as having the strongest effects on oral microbiome diversity. Overfitting of the regression model was monitored by dividing the data into ten partitions and evaluating the prediction accuracy of the model built based on nine partitions on the remaining partition.

The PICRUSt2 [71] pipeline was executed to predict metabolic pathways for the different bacterial taxa present in each species' oral cavities. Alternatively, the biochemical functions of differentially abundant taxa between pairs of species were predicted using the BioCys online server [72]. Functional enrichments of the oral microbial communities for different biochemical functions were tested using Microbiome Analyst tools [73]. Raw sequences generated for this study are available on the NCBI SRA database under BioProject (accession number PRJNA61279).

\section{Results}

None of the animals showed any signs of major acute or systematic pathology during physical examination. Only minor gum inflammation, typical of wild populations, was observed. 
Negative control reactions in all PCR setups did not produce any products. Moreover, genomic DNA libraries prepared from negative control reactions failed quality checking prior to Illumina sequencing and were discarded.

The sequencing run yielded 1219,643 paired-end, quality-filtered sequences. Each buccal swab produced 121,964 sequences on average. Brushtail possum oral swabs yielded more raw sequences compared with stoat oral swabs. The DADA2 plugin collapsed the raw sequences into 1083 unique sequence features. The blast-consensus feature classifier assigned a taxonomy rank to 590 sequence features in brushtail possums and to 549 sequence features in the stoats, with a mean posterior confidence level of $92 \%$.

In total, strains of bacteria belonging to 19 different phyla, 27 classes, 52 orders, 103 families, 163 genera and 51 known species were identified from the oral cavities of the study species. The oral cavity microbiome in both species was dominated by different strains of the phyla Proteobacteria, Firmicutes, Bacteroidetes, Fusobacteria, and Actinobacteria. Members of Tenericutes, Saccharibacteria (candidate phylumTM7), Absconditabacteria (candidate phylum SR1), Cyanobacteria, Gracilibacteria (candidate phylum GN02), Chlorobi, Spirochaetes, Acidobacteria, Thermi, Planctomycetes, Dependentiae (candidate phylum TM6), Armatimonadetes, Chloroflexi, and Thermotogae were also detected but were present at a comparatively lower abundance. Absconditabacteria(candidate phylum SR1), Gracilibacteria (candidate phylum GN02), Spirochaetes, and Thermotogae were only detected in the possum oral microbiota. Strains unique to stoat oral cavities were Chlorobi, Acidobacteria, Thermi, Planctomycetes, Armatimonadetes, and Chloroflexi. Strains of Pasteurellaceae (32.02\%), Neisseriaceae $(18.29 \%)$, Streptococcaceae $(17.76 \%)$, and Leptotrichiaceae $(10.04 \%)$ were the most abundant families in the oral cavities of brushtail possums. In stoats, members of Neisseriaceae $(22.47 \%)$, Mycoplasmataceae $(11.12 \%)$, Pasteurellaceae $(10.97 \%)$, and Flavobacteriaceae $(10.28 \%)$ dominated oral bacterial diversity (Table 1).

The variation in group-evenness and Faith phylogenetic $\alpha$-diversity indices were not statistically significant between brushtail possums and stoats $(H=3.84, p$-values $=0.05$ and $\mathrm{H}=0.24, p$-values $=0.62$, respectively). PERMANOVA test results on unweighted UniFrac metrics showed that $\beta$-diversity differed significantly between the two species (pseudo $F=3.43, p$-values $=0.007$, and 999 permutations).

Principal coordinates analysis of the oral microbiota based on Bray-Curtis, Jaccard's, and unweighted Unifrac metrics demonstrated that the oral microbiota of the brushtail possums clustered densely together, while stoat microbiota showed higher intra-individual variation and clustered more loosely. This pattern is less evident in weighted UniFrac metrics where the presence of low-abundance taxa most likely confounded the clustering pattern (Figure 1).

The linear regression summary in Gneiss indicated that approximately $45 \%$ of the variance in oral bacterial diversity were explained by our model. Taxonomic infraclass (brushtail possum versus stoat) had significantly more influence on bacterial diversity than intraspecies variation (Rdif of 0.188 versus 0.0796). The 10-fold cross-validation confirmed that within-model error was higher than prediction accuracy in all replicates, and that model overfitting was rejected.

Bacterial taxon abundance in one specific balance in the correlation tree differed significantly between possums and stoats (false discovery rate corrected coefficient $p$-values of 0.001 and 0.030 for intercept and a taxonomic rank, respectively). This balance, and its descending leaf nodes, mainly consisted of strains of Streptococcus spp., Leptotrichia spp., Heamophilus spp., and unidentified strains belonging to Pasteurellaceae and Aerrococcaceae families. 
Table 1. Abundance of different bacterial families identified from the oral microbiota of brushtail possums and stoats.

\begin{tabular}{|c|c|c|c|c|c|c|c|c|c|c|c|}
\hline \multirow{2}{*}{ Phylum } & \multirow{2}{*}{ Family } & \multicolumn{5}{|c|}{ Possum Specimens } & \multicolumn{5}{|c|}{ Stoat Specimens } \\
\hline & & a & b & c & d & e & a & $\mathbf{b}$ & c & d & e \\
\hline \multirow{26}{*}{ Actinobacteria } & Acidobacteriaceae & 2 & 0 & 0 & 9 & 6 & 0 & 0 & 0 & 0 & 0 \\
\hline & C111 & 0 & 0 & 0 & 0 & 4 & 0 & 0 & 0 & 0 & 0 \\
\hline & Actinomycetaceae & 6671 & 4399 & 6709 & 0 & 0 & 890 & 324 & 1155 & 238 & 4265 \\
\hline & Brevibacteriaceae & 5 & 7 & 0 & 11 & 7 & 0 & 0 & 0 & 0 & 0 \\
\hline & Cellulomonadaceae & 0 & 0 & 0 & 0 & 3 & 0 & 0 & 0 & 0 & 4 \\
\hline & Corynebacteriaceae & 226 & 949 & 397 & 50 & 23 & 150 & 604 & 392 & 26 & 79 \\
\hline & Dermabacteraceae & 0 & 0 & 0 & 9 & 13 & 0 & 0 & 0 & 0 & 11 \\
\hline & Dermacoccaceae & 0 & 0 & 0 & 3 & 0 & 0 & 0 & 0 & 0 & 0 \\
\hline & Dietziaceae & 0 & 4 & 0 & 0 & 0 & 0 & 0 & 0 & 0 & 0 \\
\hline & Geodermatophilaceae & 0 & 0 & 0 & 0 & 7 & 0 & 0 & 0 & 0 & 0 \\
\hline & Intrasporangiaceae & 0 & 0 & 0 & 9 & 37 & 0 & 0 & 0 & 0 & 0 \\
\hline & Kineosporiaceae & 0 & 0 & 0 & 0 & 15 & 0 & 0 & 0 & 0 & 0 \\
\hline & Microbacteriaceae & 0 & 0 & 0 & 9 & 93 & 744 & 4 & 26 & 43 & 202 \\
\hline & Micrococcaceae & 26 & 18 & 0 & 5 & 36 & 0 & 65 & 90 & 1855 & 12 \\
\hline & Nakamurellaceae & 0 & 0 & 0 & 12 & 0 & 0 & 0 & 0 & 0 & 0 \\
\hline & Nocardioidaceae & 0 & 0 & 0 & 16 & 36 & 0 & 0 & 0 & 0 & 0 \\
\hline & Propionibacteriaceae & 6064 & 30 & 8846 & 123 & 42 & 113 & 6 & 257 & 120 & 115 \\
\hline & Pseudonocardiaceae & 0 & 0 & 0 & 3 & 17 & 0 & 0 & 0 & 0 & 0 \\
\hline & Sporichthyaceae & 0 & 0 & 0 & 0 & 5 & 0 & 0 & 0 & 0 & 0 \\
\hline & Streptomycetaceae & 0 & 0 & 0 & 4 & 29 & 0 & 0 & 3 & 0 & 0 \\
\hline & Williamsiaceae & 0 & 0 & 0 & 4 & 0 & 0 & 0 & 0 & 0 & 0 \\
\hline & Coriobacteriaceae & 0 & 2 & 9 & 0 & 6 & 0 & 9 & 0 & 2 & 0 \\
\hline & Euzebyaceae & 0 & 0 & 0 & 0 & 0 & 0 & 0 & 4 & 0 & 0 \\
\hline & Gaiellaceae & 0 & 0 & 0 & 2 & 3 & 0 & 0 & 0 & 0 & 0 \\
\hline & Patulibacteraceae & 0 & 0 & 0 & 0 & 14 & 0 & 0 & 0 & 0 & 0 \\
\hline & Solirubrobacteraceae & 0 & 0 & 0 & 7 & 11 & 0 & 0 & 0 & 0 & 0 \\
\hline \multirow{12}{*}{ Bacteroidetes } & Bacteroidaceae & 31 & 9 & 5 & 18 & 4 & 6 & 0 & 3 & 165 & 0 \\
\hline & Porphyromonadaceae & 73 & 1286 & 42 & 29 & 20 & 3092 & 2093 & 466 & 482 & 5361 \\
\hline & Prevotellaceae & 38 & 63 & 53 & 35 & 91 & 156 & 572 & 62 & 157 & 494 \\
\hline & S24-7 & 0 & 0 & 0 & 0 & 0 & 0 & 0 & 4 & 7 & 4 \\
\hline & Barnesiellaceae & 0 & 0 & 0 & 0 & 7 & 0 & 0 & 0 & 0 & 0 \\
\hline & Paraprevotellaceae & 3 & 9 & 0 & 0 & 7 & 4 & 0 & 0 & 6 & 0 \\
\hline & Cyclobacteriaceae & 2 & 0 & 0 & 0 & 0 & 0 & 0 & 0 & 0 & 0 \\
\hline & Cytophagaceae & 4 & 0 & 0 & 0 & 15 & 0 & 0 & 0 & 0 & 0 \\
\hline & Flavobacteriaceae & 4887 & 23,828 & 17,570 & 2099 & 17 & 2238 & 2809 & 937 & 1856 & 5121 \\
\hline & Weeksellaceae & 11,660 & 7945 & 2085 & 4249 & 14,979 & 405 & 945 & 477 & 111 & 1068 \\
\hline & Sphingobacteriaceae & 7 & 0 & 0 & 15 & 58 & 0 & 4 & 0 & 0 & 0 \\
\hline & Chitinophagaceae & 0 & 0 & 0 & 9 & 21 & 0 & 0 & 0 & 0 & 4 \\
\hline Chloroflexi & Dolo_23 & 0 & 0 & 0 & 0 & 2 & 0 & 0 & 0 & 0 & 0 \\
\hline \multirow{24}{*}{ Firmicutes } & Bacillaceae & 13 & 4 & 6 & 5 & 12 & 5 & 0 & 0 & 0 & 0 \\
\hline & Paenibacillaceae & 0 & 0 & 0 & 0 & 0 & 5575 & 1657 & 0 & 2645 & 61 \\
\hline & Planococcaceae & 0 & 0 & 2 & 14 & 8 & 0 & 0 & 6 & 0 & 0 \\
\hline & Staphylococcaceae & 86 & 7 & 0 & 246 & 300 & 0 & 3 & 3 & 0 & 3 \\
\hline & Exiguobacteraceae & 0 & 4 & 0 & 0 & 0 & 3 & 0 & 0 & 0 & 0 \\
\hline & Thermicanaceae & 5 & 0 & 0 & 4 & 9 & 0 & 0 & 0 & 0 & 0 \\
\hline & Gemellaceae & 10,310 & 1821 & 1049 & 12,727 & 15,233 & 3438 & 829 & 84 & 2015 & 0 \\
\hline & Aerococcaceae & 429 & 4295 & 218 & 1718 & 747 & 1226 & 4145 & 113 & 1258 & 1590 \\
\hline & Carnobacteriaceae & 10 & 11 & 5 & 2 & 46 & 80 & 7 & 11 & 130 & 98 \\
\hline & Enterococcaceae & 7 & 0 & 5 & 0 & 8 & 0 & 7 & 0 & 6 & 5 \\
\hline & Lactobacillaceae & 4 & 4 & 0 & 0 & 28 & 0 & 2 & 14 & 12 & 0 \\
\hline & Leuconostocaceae & 0 & 3 & 0 & 0 & 8 & 0 & 0 & 0 & 0 & 0 \\
\hline & Streptococcaceae & 51 & 840 & 132 & 3196 & 12,656 & 26,169 & 19,442 & 14,569 & 32,630 & 11,017 \\
\hline & Turicibacteraceae & 0 & 0 & 0 & 0 & 3 & 0 & 0 & 0 & 14 & 0 \\
\hline & Clostridiaceae & 170 & 13 & 52 & 458 & 190 & 0 & 0 & 7 & 67 & 13 \\
\hline & Lachnospiraceae & 24 & 31 & 22 & 2 & 41 & 511 & 1153 & 175 & 814 & 191 \\
\hline & Peptococcaceae & 0 & 0 & 0 & 0 & 0 & 0 & 0 & 9 & 0 & 4 \\
\hline & Peptostreptococcaceae & 37 & 6 & 0 & 166 & 53 & 0 & 28 & 26 & 0 & 2 \\
\hline & Ruminococcaceae & 20 & 12 & 6 & 7 & 42 & 4 & 5 & 0 & 0 & 34 \\
\hline & Veillonellaceae & 45 & 62 & 57 & 19 & 35 & 20 & 1666 & 97 & 454 & 57 \\
\hline & Acidaminobacteraceae & 0 & 0 & 0 & 0 & 0 & 0 & 0 & 73 & 0 & 12 \\
\hline & Mogibacteriaceae & 0 & 0 & 0 & 0 & 0 & 0 & 2 & 0 & 0 & 3 \\
\hline & Tissierellaceae & 45 & 0 & 7 & 9 & 6 & 4 & 0 & 15 & 0 & 8 \\
\hline & Erysipelotrichaceae & 0 & 1622 & 6 & 0 & 11 & 15 & 11 & 23 & 145 & 50 \\
\hline
\end{tabular}


Table 1. Cont.

\begin{tabular}{|c|c|c|c|c|c|c|c|c|c|c|c|}
\hline \multirow{2}{*}{ Phylum } & \multirow{2}{*}{ Family } & \multicolumn{5}{|c|}{ Possum Specimens } & \multicolumn{5}{|c|}{ Stoat Specimens } \\
\hline & & a & $\mathbf{b}$ & c & d & e & $\mathbf{a}$ & $\mathbf{b}$ & c & d & e \\
\hline \multirow{2}{*}{ Fusobacteria } & Fusobacteriaceae & 21 & 20 & 19 & 54 & 66 & 5151 & 17,078 & 1478 & 7176 & 15,051 \\
\hline & Leptotrichiaceae & 784 & 26 & 7 & 0 & 55 & 3050 & 28,266 & 2224 & 7229 & 17,960 \\
\hline \multirow{35}{*}{ Proteobacteria } & Caulobacteraceae & 6 & 0 & 0 & 5 & 10 & 0 & 0 & 0 & 0 & 0 \\
\hline & Bradyrhizobiaceae & 0 & 0 & 0 & 9 & 0 & 0 & 0 & 0 & 0 & 0 \\
\hline & Brucellaceae & 0 & 0 & 0 & 0 & 6 & 0 & 0 & 0 & 0 & 0 \\
\hline & Hyphomicrobiaceae & 0 & 0 & 0 & 0 & 9 & 0 & 0 & 0 & 0 & 0 \\
\hline & Methylobacteriaceae & 0 & 0 & 0 & 14 & 72 & 0 & 0 & 0 & 0 & 0 \\
\hline & Methylocystaceae & 0 & 0 & 0 & 0 & 6 & 0 & 0 & 0 & 0 & 0 \\
\hline & Rhizobiaceae & 0 & 11 & 0 & 14 & 30 & 0 & 0 & 0 & 0 & 0 \\
\hline & Rhodobacteraceae & 0 & 0 & 0 & 3 & 11 & 0 & 0 & 0 & 0 & 4 \\
\hline & Acetobacteraceae & 5 & 0 & 2 & 0 & 29 & 0 & 0 & 0 & 0 & 0 \\
\hline & Rhodospirillaceae & 0 & 0 & 0 & 0 & 3 & 0 & 0 & 0 & 0 & 0 \\
\hline & mitochondria & 0 & 0 & 0 & 0 & 8 & 0 & 0 & 0 & 2 & 0 \\
\hline & Erythrobacteraceae & 0 & 0 & 0 & 0 & 8 & 0 & 0 & 0 & 0 & 0 \\
\hline & Sphingomonadaceae & 6 & 0 & 0 & 4 & 91 & 6 & 0 & 0 & 0 & 0 \\
\hline & Alcaligenaceae & 4 & 0 & 0 & 0 & 0 & 3 & 0 & 2 & 23 & 4 \\
\hline & Burkholderiaceae & 6992 & 29,794 & 1774 & 1606 & 66 & 1099 & 239 & 208 & 86 & 83 \\
\hline & Comamonadaceae & 2032 & 39 & 1616 & 7 & 56 & 99 & 0 & 40 & 14 & 158 \\
\hline & Oxalobacteraceae & 0 & 4 & 0 & 10 & 76 & 0 & 0 & 4 & 0 & 0 \\
\hline & Methylophilaceae & 6 & 0 & 0 & 0 & 0 & 0 & 0 & 0 & 0 & 0 \\
\hline & Neisseriaceae & 11,609 & 28,742 & 19,824 & 10,454 & 35,160 & 25,358 & 10,979 & 22,580 & 43,075 & 4938 \\
\hline & Rhodocyclaceae & 9 & 0 & 0 & 7 & 6 & 8 & 0 & 0 & 6 & 0 \\
\hline & Bdellovibrionaceae & 0 & 0 & 0 & 0 & 2 & 0 & 0 & 0 & 0 & 0 \\
\hline & Polyangiaceae & 6 & 0 & 0 & 0 & 0 & 0 & 0 & 0 & 0 & 0 \\
\hline & Syntrophobacteraceae & 0 & 0 & 0 & 0 & 4 & 0 & 0 & 0 & 0 & 0 \\
\hline & Campylobacteraceae & 3 & 0 & 0 & 0 & 11 & 71 & 54 & 19 & 29 & 55 \\
\hline & Helicobacteraceae & 71 & 4 & 95 & 128 & 3686 & 0 & 0 & 0 & 0 & 0 \\
\hline & Chromatiaceae & 0 & 0 & 4 & 0 & 0 & 0 & 0 & 0 & 0 & 0 \\
\hline & Cardiobacteriaceae & 3223 & 3521 & 6280 & 2 & 0 & 32 & 0 & 185 & 16 & 387 \\
\hline & Enterobacteriaceae & 41 & 40 & 24 & 35 & 140 & 0 & 0 & 0 & 0 & 0 \\
\hline & Halomonadaceae & 3 & 0 & 0 & 0 & 0 & 0 & 0 & 0 & 0 & 0 \\
\hline & Pasteurellaceae & 6193 & 9601 & 9533 & 5981 & 20,350 & 56,748 & 27,617 & 48,242 & 43,199 & 11,382 \\
\hline & Moraxellaceae & 8 & 0 & 0 & 66 & 281 & 1709 & 2623 & 588 & 298 & 59 \\
\hline & Pseudomonadaceae & 5 & 13 & 6 & 13 & 26 & 0 & 0 & 0 & 0 & 0 \\
\hline & Vibrionaceae & 0 & 0 & 0 & 0 & 4 & 0 & 0 & 2 & 0 & 0 \\
\hline & Sinobacteraceae & 0 & 0 & 0 & 0 & 5 & 0 & 0 & 0 & 0 & 0 \\
\hline & Xanthomonadaceae & 16 & 3 & 0 & 26 & 77 & 2 & 0 & 0 & 0 & 0 \\
\hline Spirochaetes & Spirochaetaceae & 0 & 0 & 0 & 0 & 0 & 0 & 3 & 36 & 0 & 3 \\
\hline TM7 & $F 16$ & 0 & 0 & 0 & 0 & 0 & 0 & 0 & 0 & 7 & 0 \\
\hline \multirow{3}{*}{ Tenericutes } & Acholeplasmataceae & 0 & 0 & 0 & 0 & 0 & 0 & 0 & 51 & 0 & 0 \\
\hline & Anaeroplasmataceae & 0 & 0 & 0 & 0 & 0 & 0 & 0 & 0 & 6 & 0 \\
\hline & Mycoplasmataceae & 27,690 & 2951 & 13,142 & 4572 & 4017 & 0 & 4 & 14 & 0 & 0 \\
\hline Thermotogae & Thermotogaceae & 0 & 0 & 0 & 0 & 0 & 0 & 0 & 0 & 2 & 0 \\
\hline \multirow{2}{*}{ Thermi } & Trueperaceae & 0 & 0 & 0 & 2 & 0 & 0 & 0 & 0 & 0 & 0 \\
\hline & Thermaceae & 6 & 0 & 0 & 0 & 0 & 0 & 0 & 0 & 0 & 0 \\
\hline
\end{tabular}

In the modular network analysis, graph density was similar between brushtail possums and stoats (0.12). The average degree of node connectivity estimated for stoats was higher than that for brushtail possums (16.62 versus 11.01, respectively). The most connected nodes in the brushtail possum oral microbiome network consisted of Campylobacter sp. $(n=35)$, Saccharibacteria sp. $(n=34)$, and Paenibacilus sp. $(n=33)$. In stoats, Patulibacter sp. $(n=58)$, Curtobacterium sp. $(n=58)$, Carnobacterium sp. $(n=58)$, and Streptomyces sp. $(n=56)$ demonstrated the highest degree of node connectivity (Figure 2).

Metabolic pathway analysis of oral microbiome diversity revealed that the microbial taxa in the oral cavities of both species are functionally enriched for biochemical pathways involved in the biosynthesis of various metabolites (e.g., vitamins, aminoamides and organic carbon compounds), starch and sucrose metabolism, steroid hormone degradation, and antimicrobial activities (e.g., streptomycin biosynthesis) (Table 2). Functional content analysis of the bacterial taxa that differ in abundance between the two species illustrated that the majority of these bacteria are involved in the biosynthesis of different metabolites, biochemical degradation and assimilation, energy production, respiration, and detoxification. 

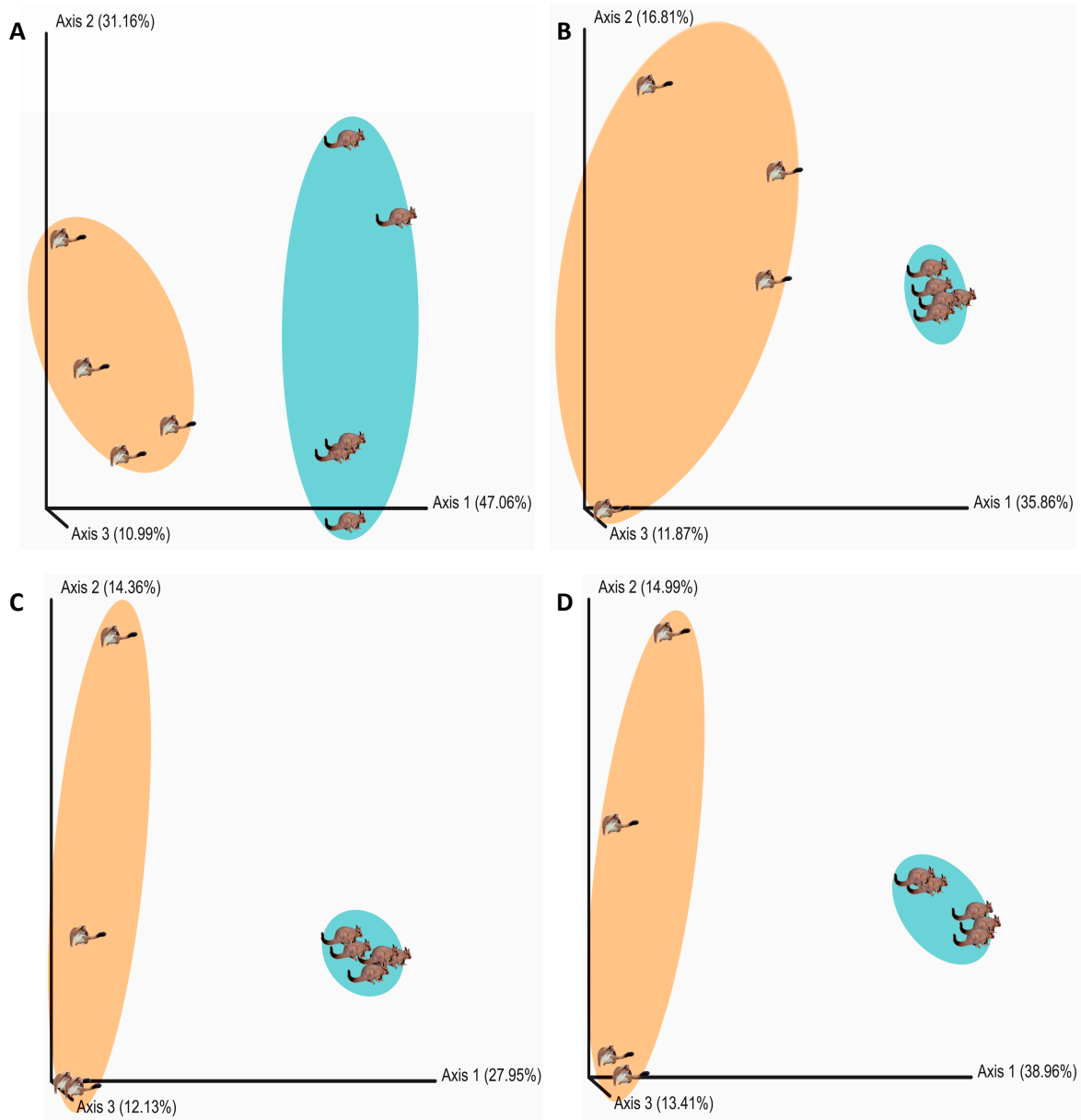

Figure 1. Component analyses of different $\alpha$ and $\beta$ diversity indices in the oral microbiota of brushtail possums and stoats. (A) Weighted Unifrac, (B) unweighted Unifrac, (C) Jaccard's index, and (D) Bray Curtis. For each axis, the percentage of variance explained by that axis is indicated. brushtail possums (turquois) and stoats(orange).

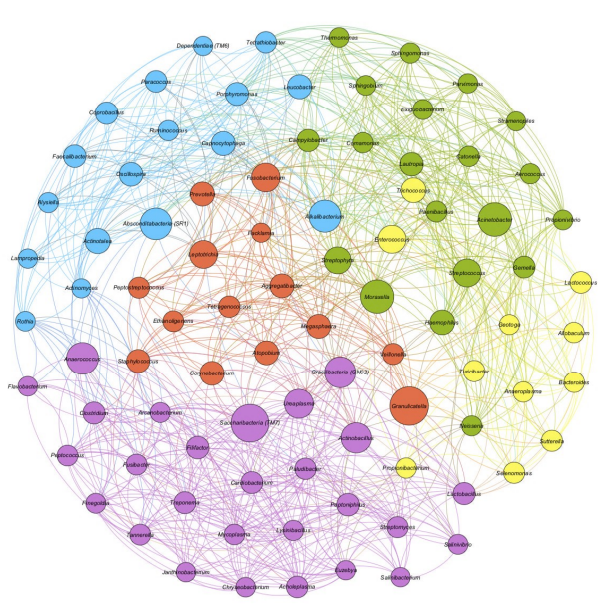

A

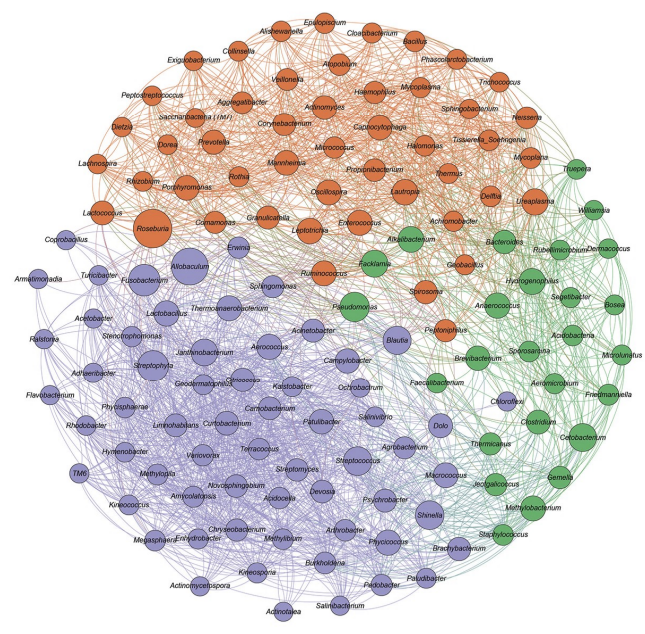

B

Figure 2. Modular network analysis of the bacterial taxa identified from (A) brushtail possums' and (B) stoats' oral microbiota. Node coloursrepresent the co-occurring bacterial taxa (modules). The node sizes are proportional to the degree of between centrality, and edges are coloured based on the node of origin. 
Table 2. Functional enrichment of biochemical pathways identified from the oral microbiota of brushtail possums and stoats (names, total number of pathways and $p$-values).

\begin{tabular}{|c|c|c|c|c|}
\hline \multirow{2}{*}{ Pathway } & \multicolumn{2}{|c|}{ Possums } & \multicolumn{2}{|c|}{ Stoats } \\
\hline & Total & $p$-Values & Total & $p$-Values \\
\hline Lipopolysaccharide biosynthesis & 17 & 0 & 17 & 0 \\
\hline Biosynthesis of amino acids & 222 & $<0.001$ & 222 & $<0.001$ \\
\hline Peptidoglycan biosynthesis & 13 & $<0.001$ & 13 & $<0.001$ \\
\hline Terpenoid backbone biosynthesis & 23 & $<0.001$ & 23 & $<0.001$ \\
\hline Streptomycin biosynthesis & 12 & $<0.001$ & 12 & $<0.001$ \\
\hline Polyketide sugar unit biosynthesis & 4 & $<0.05$ & 4 & $<0.05$ \\
\hline Valine, leucine and isoleucine biosynthesis & 15 & $<0.05$ & - & - \\
\hline Folate biosynthesis & 29 & $<0.05$ & - & - \\
\hline Porphyrin and chlorophyll metabolism & 69 & $<0.001$ & 69 & $<0.001$ \\
\hline Alanine, aspartate and glutamate metabolism & 62 & $<0.001$ & 62 & $<0.001$ \\
\hline Arginine and proline metabolism & 115 & $<0.01$ & 115 & $<0.01$ \\
\hline Cysteine and methionine metabolism & 71 & $<0.01$ & 71 & $<0.01$ \\
\hline Glycine, serine and threonine metabolism & 78 & $<0.01$ & 78 & $<0.01$ \\
\hline D-Glutamine and D-glutamate metabolism & 6 & $<0.01$ & 6 & $<0.01$ \\
\hline Thiamine metabolism & 23 & $<0.01$ & 23 & $<0.01$ \\
\hline Starch and sucrose metabolism & 65 & $<0.01$ & 65 & $<0.05$ \\
\hline Glyoxylate and dicarboxylate metabolism & 51 & $<0.01$ & 51 & $<0.05$ \\
\hline Biotin metabolism & 19 & $<0.05$ & 19 & $<0.05$ \\
\hline Riboflavin metabolism & 22 & $<0.05$ & 22 & $<0.05$ \\
\hline Amino sugar and nucleotide sugar metabolism & 64 & $<0.05$ & 64 & $<0.05$ \\
\hline Carbon metabolism & 249 & $<0.05$ & 249 & $<0.05$ \\
\hline Butanoate metabolism & 61 & $<0.05$ & - & - \\
\hline Nicotinate and nicotinamide metabolism & 36 & $<0.05$ & - & - \\
\hline beta-Alanine metabolism & - & - & 36 & $<0.05$ \\
\hline Vitamin B6 metabolism & - & - & 12 & $<0.05$ \\
\hline Phenylalanine metabolism & 41 & $<0.05$ & 41 & $<0.01$ \\
\hline Xylene degradation & 20 & $<0.01$ & 20 & $<0.01$ \\
\hline Steroid degradation & 9 & $<0.05$ & 9 & $<0.05$ \\
\hline Lysine degradation & - & - & 30 & $<0.05$ \\
\hline Synthesis and degradation of ketone bodies & 5 & $<0.05$ & 5 & $<0.05$ \\
\hline Pentose and glucuronate interconversions & 41 & $<0.05$ & 41 & $<0,01$ \\
\hline Carbon fixation in photosynthetic organisms & 35 & $<0.05$ & 35 & $<0.05$ \\
\hline Pentose phosphate pathway & - & - & 63 & $<0.01$ \\
\hline
\end{tabular}

\section{Discussion}

Recent advances in comparative genomics, biochemistry, and developmental biology have made it possible to demarcate species boundaries with an unprecedented level of accuracy. However, the interdependence between hosts and a wide diversity of microorganisms that reside in and on an individual has provided a new set of challenges in defining what constitutes an individual.

In the current study, we have described and discussed the taxonomic diversity and functional content of the oral microbiome of brushtail possums and stoats in New Zealand. The number of sequence features identified in the oral cavities of both species resembles that reported for humans [74]. However, the sequence features that were assigned the taxonomy rank of genus or species were limited, and potentially represented a high level of concealed microbial diversity that is only broadly known to science.

The oral microbiota in stoats and brushtail possums shared common features with those reported from other mammals. In both species, the oral microbiota were dominated by a small number of taxa, while other taxa were comparatively rare. The abundant bacterial taxa have been ubiquitously reported in different herbivorous, carnivorous, and omnivorous mammal species (Figure 3) [23-30]. 

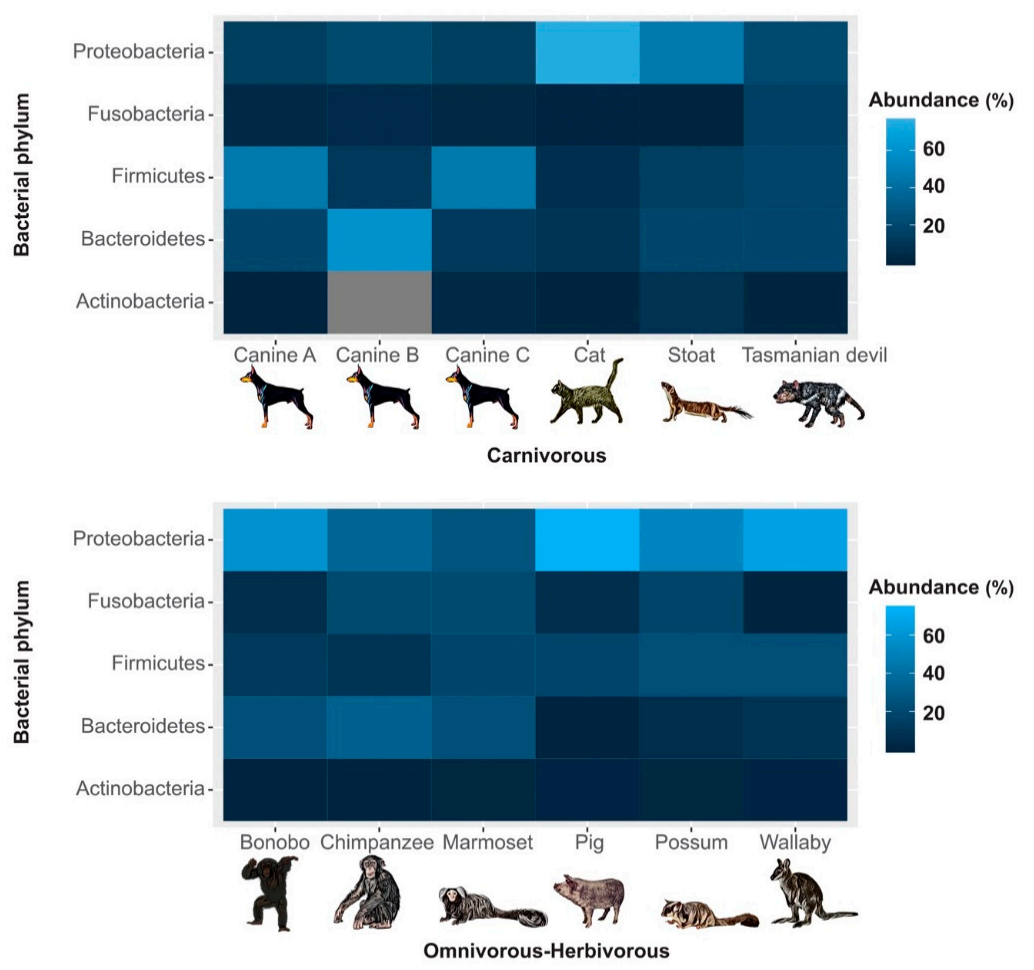

Figure 3. Major components of the oral bacterial communities of a selected number of carnivorous (top) andomnivorous-herbivorous (bottom) mammals. Colour intensities indicate the percentage abundance of five major bacterial phyla.

Diet has been suggested as one of the major determinants of oral microbial diversity [75-78]. However, consuming a similar diet is not necessarily a good predictor of oral microbiome diversity. For example, the microbiome diversity of pig (omnivore), cat (carnivore) and wallaby (herbivore) is quite similar, whereas the closely related chimpanzees and bonobos show considerable differences. In the present study, oral microbiome samples were obtained from several different niches within the oral cavity. Previous studies have shown that each niche may harbour a unique microbial community, and direct comparisons with such studies are thus limited by the fact that we pooled samples from multiple niches [79].

Our data suggest a potential link between diet and the presence of some bacterial taxa, and the biochemical functions they may perform in the oral cavity. For instance, a plant polysaccharide metabolising taxon, Treponema sp., was completely absent from the oral microbiota of the carnivorous stoat. High diversity of Firmicutes in brushtail possum oral microbiota most likely reflects the presence of staple plant-based polysaccharides in their omnivorous diet (Figures 4 and 5). The distal digestive tract in this species consists of a well-developed caecum and an enlarged proximal colon that act as fermentation chambers [80]. Firmicutes bacteria in the oral cavity of brushtail possums can initiate an early digestion step that ameliorates overall energy uptake efficiency. The absence of enrichment for biochemical pathways involved in vitamin B6 (pyridoxine) biosynthesis in the brushtail possum's oral microbiome is also consistent with a diet rich in plants. Similarly, lack of metabolic pathways to biosynthesise essential aminoacids, such as valine, leucine, and isoleucine, in the stoats' oral microbiota may reflect a high intake of animal protein in the diet. 


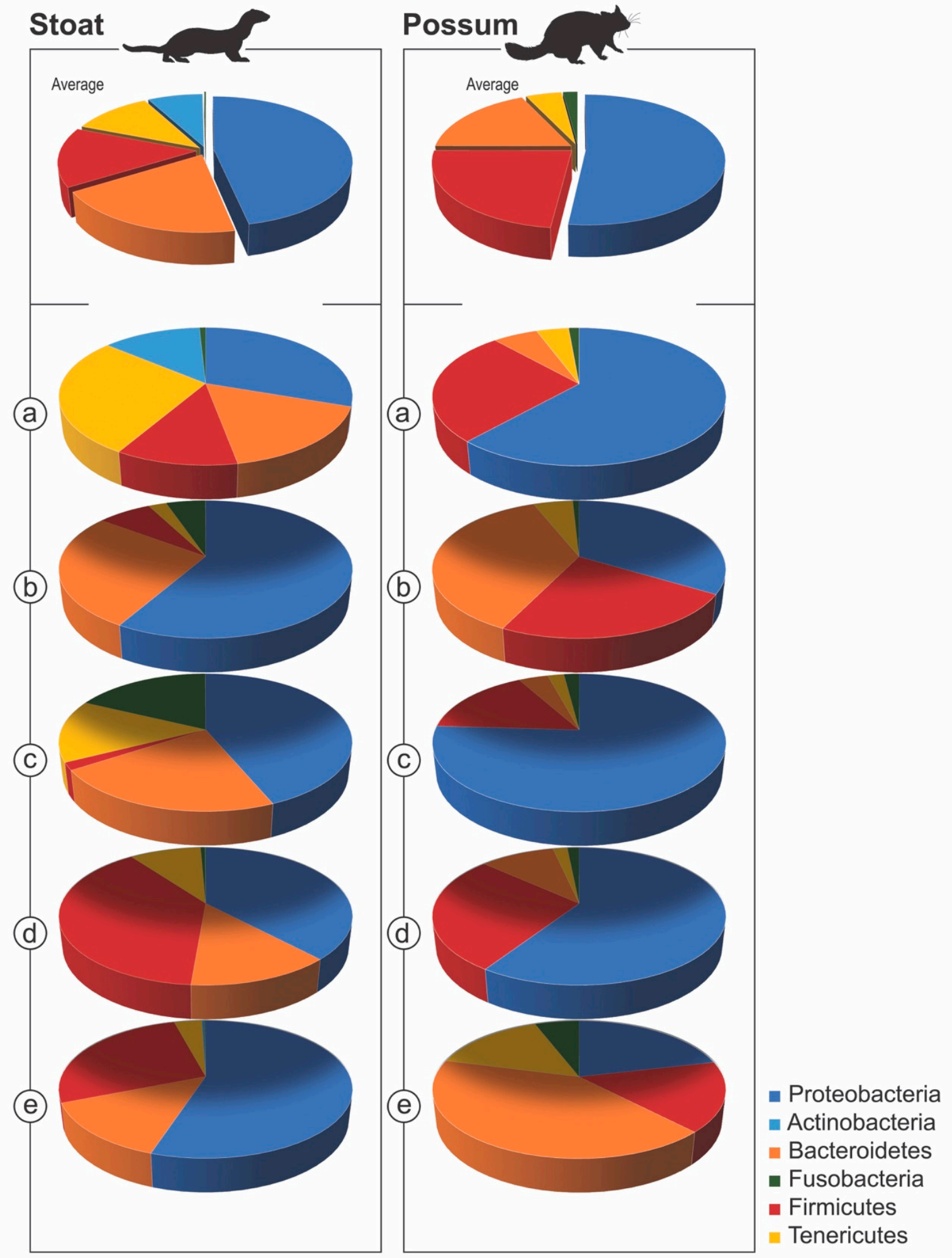

Figure 4. Inter- and intra-specific variations in the abundance of five core bacterial taxa from the oral cavities of brushtail possums and stoats. The top figure for each species depicts averages, and a-e show the variation between different individuals. 

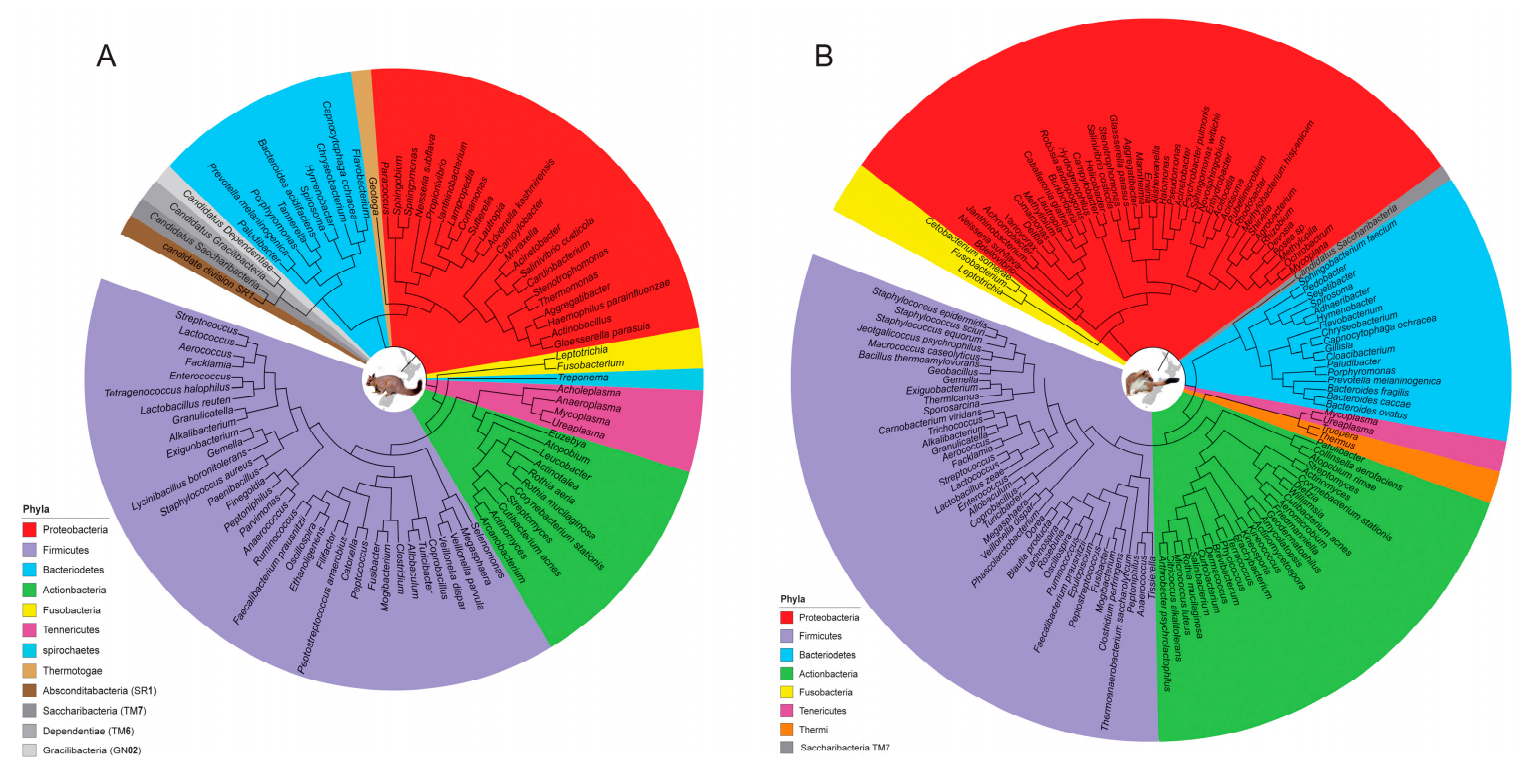

Figure 5. Phylogenetic trees showing bacterial taxa identified at the genus or species level identified from the oral cavities of (A) brushtail possums and (B) stoats. Colours represent different bacterial phyla.

Our results are amongst the first to report the presence of culture-independent candidate phylum TM6 (Dependentiae), thermophilic Thermotogae, Armatimonadetes (OP10) and Acidobacteria from the oral cavities of wild mammals. Reduced genome size and a limited biochemical repertoire in TM6 (Dependentiae) bacteria is indicative of an obligate endosymbiotic or parasitic lifestyle in the oral cavity [81]. Strains of Thermotogae, Armatimonadetes (OP10), and Actinobacteria have been reported from the microbiota in the gut of pregnant rats (Rattus norvegicus) [82], in the human oral cavity [83], and in the intestines of rice frogs (Fejervaryalimnocharis) [84]. The origin and functional significance of these taxa in the oral microbiota of the study species remain to be discovered.

The considerable intraspecific variation in the oral microbial diversity of each study species (Figures 4 and 5) suggests the influence of variables other than diet that were more difficult to control. These may include genetic and physiological factors, as well as differences in the environment prior to capture. These need to be taken into consideration to better understand the complexity of microbiome diversity [85-88].

Microorganisms in the alimentary tract represent a subset of the microbial diversity found in the environment. The exact mechanisms by which the host and its resident microbiome differentially select specific microbial diversity and functional content from the environment is unknown. However, earlier studies have shown that microbial diversity can be strongly predicted by the genetic make-up of the host species [15,89-97]. For examples, polymorphisms in the immunity-related gene interleukin-2 [90] and genes involved in core metabolic pathways, such as nucleotide-binding oligomerisation domain-containing protein 2 [91] and fucosyltransferase 2 [94], have been linked to a specific microbiome structure in the host species.

Despite considerable intra- and interspecific variations in oral microbiota, both species nonetheless display significant similarities in the metabolic functions of their oral bacterial communities. The observed pattern substantiates the idea that different hosts may assemble taxonomic diversity and functional content of their microbiome in different ways, but with a high level of taxonomic and functional redundancy that prevents a host's dependency on a limited number of bacterial taxa [98-100]. Sharpton [101] suggested that the functional content of the microbiome can be more heritable than its taxonomic diversity.

Species in the current study have been subjected to intensive population control measures using a combination of toxins and trapsfor more than 60 years. While numerous studies have underlined the 
critical role that gut microbiota play in drug and xenobiotic substance metabolism [102], the role of microbial communities in the proximal alimentary tract is yet to be understood.

As conservation efforts to eradicate invasive species intensify around the globe, focusing on the microgenome rather than the slowly-evolving host genome in genetically deprived invasive species presents an under-appreciated means of studying evolutionary responses to altered environments over a short time-scale. Future comparative studies should focus on studying microbiome diversity in a larger sample of individuals from both native and invaded ranges, and investigate the significance of bacterial communities in modulating the host's physiological and behavioural responses. Such studies would benefit from a considerably more complex study design than the one described here, as they would require that the roles of biotic and abiotic factors be detangled, while controlling for the confounding effects of the host's diet, physiological condition, sex, age, and whether individuals were sampled in the wild or had spent some time in captivity.

\section{Conclusions}

Our study highlights the critical role that a combination of genetic, physiological, and environmental factors plays in shaping oral microbiome diversity. The integrated anatomical, metabolic and immunological fitness of the host and its associated microbiome depend on a combination of concurrent selective and random changes in the genomes of both the host and its microbiome in response to changing environmental conditions.

Author Contributions: Conceptualisation, A.E.-K., A.M.P., J.G.R., E.C.M.; Methodology, A.E.-K., A.M.P., J.G.R., E.C.M., P.R.T.; Validation, A.E.-K., I.B., H.A.; Formal Analysis, A.E.-K., I.B., H.A.; Investigation, A.E.-K., I.B., H.A., J.B.; Resources, P.R.T., B.J.v.V., A.M.P., J.G.R., E.C.M.; Writing-Original Draft Preparation, A.E.-K., P.R.T., I.B., H.A., J.B., B.J.v.V., A.M.P., J.G.R., E.C.M.; Writing-Review \& Editing, A.E.-K., P.R.T., I.B., H.A., J.B., B.J.v.V., A.M.P., J.G.R., E.C.M.; Supervision, P.R.T., A.M.P., B.J.v.V., J.G.R., E.C.M.; Funding Acquisition, P.R.T., B.J.v.V., A.M.P., J.G.R., E.C.M. All authors have read and agreed to the published version of the manuscript.

Funding: This study was funded by the New Zealand Ministry of Business, Innovation and Employment under contract number LINX0902 to Lincoln University. Analytical platforms were provided by South African National Research Fund grant number110728 to B.J.v.V.

Acknowledgments: The authors acknowledge Andrea Azcarate-Peril from the University of North Carolina, and Candor Csnayi and Miklos Heltai from SzentIstván University in Hungary for their support. We would like to thank two anonymous reviewers and Sina Rahmaty for their constructive comments. Computational resources were provided by the Center for High Performance Computing (CHPC) in Cape Town and the University of Johannesburg IT service.

Conflicts of Interest: Authors declare no conflict of interest.

\section{References}

1. Dyall, S.D.; Brown, M.T.; Johnson, P.J. Ancient Invasions: From Endosymbionts to Organelles. Science 2004, 304, 253-257. [CrossRef] [PubMed]

2. Horiike, T.; Hamada, K.; Miyata, D.; Shinozawa, T. The Origin of Eukaryotes Is Suggested as the Symbiosis of Pyrococcus into Г-Proteobacteria by Phylogenetic Tree Based on Gene Content. J. Mol. Evol. 2004, 59, 606-619. [CrossRef] [PubMed]

3. Rosenberg, E.; Zilber-Rosenberg, I. Microbes Drive Evolution of Animals and Plants: The Hologenome Concept. MBio 2016, 7, e01395-15. [CrossRef] [PubMed]

4. Qin, J.; Li, R.; Raes, J.; Arumugam, M.; Burgdorf, K.S.; Manichanh, C.; Nielsen, T.; Pons, N.; Levenez, F.; Yamada, T. A Human Gut Microbial Gene Catalogue Established by Metagenomic Sequencing. Nature 2010, 464, 59-65. [CrossRef] [PubMed]

5. Apprill, A. Marine Animal Microbiomes: Toward Understanding Host-Microbiome Interactions in a Changing Ocean. Front. Mar. Sci. 2017, 4, 222. [CrossRef]

6. Dethlefsen, L.; Eckburg, P.B.; Bik, E.M.; Relman, D.A. Assembly of the Human Intestinal Microbiota. Trends Ecol. Evol. 2006, 21, 517-523. [CrossRef]

7. Lee, Y.K.; Mazmanian, S.K. Has the Microbiota Played a Critical Role in the Evolution of the Adaptive Immune System? Science 2010, 330, 1768-1773. [CrossRef] 
8. Archie, E.A.; Theis, K.R. Animal Behaviour Meets Microbial Ecology. Anim. Behav. 2011, 82, $425-436$. [CrossRef]

9. McCutcheon, J.P.; Von Dohlen, C.D. An Interdependent Metabolic Patchwork in the Nested Symbiosis of Mealybugs. Curr. Biol. 2011, 21, 1366-1372. [CrossRef]

10. Brucker, R.M.; Bordenstein, S.R. The Capacious Hologenome. Zoology 2013, 116, 260-261. [CrossRef]

11. Wang, J.; Kalyan, S.; Steck, N.; Turner, L.M.; Harr, B.; Künzel, S.; Vallier, M.; Häsler, R.; Franke, A.; Oberg, H.-H. Analysis of Intestinal Microbiota in Hybrid House Mice Reveals Evolutionary Divergence in a Vertebrate Hologenome. Nat. Commun. 2015, 6, 6440. [CrossRef]

12. Cheng, D.; Chen, S.; Huang, Y.; Pierce, N.E.; Riegler, M.; Yang, F.; Zeng, L.; Lu, Y.; Liang, G.; Xu, Y. Symbiotic Microbiota May Reflect Host Adaptation by Resident to Invasive Ant Species. PLoS Pathog. 2019, 15, e1007942. [CrossRef] [PubMed]

13. Siebert, J.C.; Görg, C.; Palmer, B.; Lozupone, C. Visualizing Microbiome-Immune System Interplay. Fut. Med. 2019, 11, 2. [CrossRef] [PubMed]

14. Figueroa-Romero, C.; Guo, K.; Murdock, B.J.; Paez-Colasante, X.; Bassis, C.M.; Mikhail, K.A.; Raue, K.D.; Evans, M.C.; Taubman, G.F.; McDermott, A.J. Temporal Evolution of the Microbiome, Immune System and Epigenome with Disease Progression in Als Mice. Dis. Models Mech. 2020, 13, dmm041947. [CrossRef]

15. Rawls, J.F.; Mahowald, M.A.; Ley, R.E.; Gordon, J.I. Reciprocal Gut Microbiota Transplants from Zebrafish and Mice to Germ-Free Recipients Reveal Host Habitat Selection. Cell 2006, 127, 423-433. [CrossRef]

16. Rosenberg, E.; Zilber-Rosenberg, I. The Hologenome Concept: Human, Animal and Plant Microbiota; Springer: New York, NY, USA, 2014; pp. 1-178.

17. Zilber-Rosenberg, I.; Rosenberg, E. Role of Microorganisms in the Evolution of Animals and Plants: The Hologenome Theory of Evolution. FEMS Microbiol. Rev. 2008, 32, 723-735. [CrossRef]

18. Theis, K.R.; Dheilly, N.M.; Klassen, J.L.; Brucker, R.M.; Baines, J.F.; Bosch, T.C.; Cryan, J.F.; Gilbert, S.F.; Goodnight, C.J.; Lloyd, E.A. Getting the Hologenome Concept Right: An Eco-Evolutionary Framework for Hosts and Their Microbiomes. Msystems 2016, 1, e0028-16. [CrossRef] [PubMed]

19. Gill, S.R.; Pop, M.; DeBoy, R.T.; Eckburg, P.B.; Turnbaugh, P.J.; Samuel, B.S.; Gordon, J.I.; Relman, D.A.; Fraser-Liggett, C.M.; Nelson, K.E. Metagenomic Analysis of the Human Distal Gut Microbiome. Science 2006, 312, 1355-1359. [CrossRef] [PubMed]

20. Barker, C.J.; Gillett, A.; Polkinghorne, A.; Timms, P. Investigation of the Koala (Phascolarctos cinereus) Hindgut Microbiome Via 16s Pyrosequencing. Vet. Microbiol. 2013, 167, 554-564. [CrossRef]

21. Moeller, A.H. The Shrinking Human Gut Microbiome. Curr. Opin. Microbiol. 2017, 38, 30-35. [CrossRef]

22. Raymann, K.; Moeller, A.H.; Goodman, A.L.; Ochman, H. Unexplored Archaeal Diversity in the Great Ape Gut Microbiome. MSphere 2017, 2, e00017-e00026. [CrossRef]

23. Cheng, Y.; Fox, S.; Pemberton, D.; Hogg, C.; Papenfuss, A.T.; Belov, K. The Tasmanian Devil Microbiome-Implications for Conservation and Management. Microbiome 2015, 3, 76. [CrossRef] [PubMed]

24. Chhour, K.-L.; Hinds, L.A.; Jacques, N.A.; Deane, E.M. An Observational Study of the Microbiome of the Maternal Pouch and Saliva of the Tammar Wallaby, Macropus Eugenii, and of the Gastrointestinal Tract of the Pouch Young. Microbiology 2010, 156, 798-808. [CrossRef] [PubMed]

25. Davis, E.M. Gene Sequence Analyses of the Healthy Oral Microbiome in Humans and Companion Animals: A Comparative Review. J. Vet. Dent. 2016, 33, 97-107. [CrossRef] [PubMed]

26. Dewhirst, F.E.; Klein, E.A.; Thompson, E.C.; Blanton, J.M.; Chen, T.; Milella, L.; Buckley, C.M.; Davis, I.J.; Bennett, M.-L.; Marshall-Jones, Z.V. The Canine Oral Microbiome. PLoS ONE 2012, 7, e36067. [CrossRef]

27. Li, J.; Nasidze, I.; Quinque, D.; Li, M.; Horz, H.-P.; André, C.; Garriga, R.M.; Halbwax, M.; Fischer, A.; Stoneking, M. The Saliva Microbiome of Pan and Homo. BMC Microbiol. 2013, 13, 204. [CrossRef]

28. Lowe, B.A.; Marsh, T.L.; Isaacs-Cosgrove, N.; Kirkwood, R.N.; Kiupel, M.; Mulks, M.H. Defining the "Core Microbiome" of the Microbial Communities in the Tonsils of Healthy Pigs. BMC Microbiol. 2012, 12, 20. [CrossRef]

29. Sturgeon, A.; Pinder, S.; Costa, M.; Weese, J. Characterization of the Oral Microbiota of Healthy Cats Using Next-Generation Sequencing. Vet. J. 2014, 201, 223-229. [CrossRef]

30. Takehara, S.; Zeredo, J.L.; Kumei, Y.; Kagiyama, K.; Fukasawa, K.; Oshiro, A.; Ueno, M.; Kojimahara, N.; Minakuchi, S.; Kawaguchi, Y. Characterization of Oral Microbiota in Marmosets: Feasibility of Using the Marmoset as a Human Oral Disease Model. PLoS ONE 2019, 14, e0207560. [CrossRef] 
31. Dewhirst, F.E.; Chen, T.; Izard, J.; Paster, B.J.; Tanner, A.C.; Yu, W.-H.; Lakshmanan, A.; Wade, W.G. The Human Oral Microbiome. J. Bacteriol. 2010, 192, 5002-5017. [CrossRef]

32. Gomez, A.; Espinoza, J.L.; Harkins, D.M.; Leong, P.; Saffery, R.; Bockmann, M.; Torralba, M.; Kuelbs, C.; Kodukula, R.; Inman, J. Host Genetic Control of the Oral Microbiome in Health and Disease. Cell Host Microbe 2017, 22, 269-278.e3. [CrossRef] [PubMed]

33. Beck, J.D.; Slade, G.; Offenbacher, S. Oral Disease, Cardiovascular Disease and Systemic Inflammation. Periodontology 2000 2000, 23, 110-120. [CrossRef]

34. Castellarin, M.; Warren, R.L.; Freeman, J.D.; Dreolini, L.; Krzywinski, M.; Strauss, J.; Barnes, R.; Watson, P.; Allen-Vercoe, E.; Moore, R.A. Fusobacterium Nucleatum Infection Is Prevalent in Human Colorectal Carcinoma. Genome Res. 2012, 22, 299-306. [CrossRef] [PubMed]

35. Seymour, G.; Ford, P.; Cullinan, M.; Leishman, S.; Yamazaki, K. Relationship between Periodontal Infections and Systemic Disease. Clin. Microbiol. Infect. 2007, 13, 3-10. [CrossRef] [PubMed]

36. Zarco, M.; Vess, T.; Ginsburg, G. The Oral Microbiome in Health and Disease and the Potential Impact on Personalized Dental Medicine. Oral Dis. 2012, 18, 109-120. [CrossRef]

37. Wilmshurst, J.M.; Anderson, A.J.; Higham, T.F.; Worthy, T.H. Dating the Late Prehistoric Dispersal of Polynesians to New Zealand Using the Commensal Pacific Rat. Proc. Natl. Acad. Sci. USA 2008, 105, 7676-7680. [CrossRef]

38. Emami-Khoyi, A.; Paterson, A.M.; Hartley, D.A.; Boren, L.J.; Cruickshank, R.H.; Ross, J.G.; Murphy, E.C.; Else, T.-A. Mitogenomics Data Reveal Effective Population Size, Historical Bottlenecks, and the Effects of Hunting on New Zealand Fur Seals (Arctocephalus forsteri). Mitochondrial DNA Part A 2018, 29, 567-580. [CrossRef]

39. Murphy, E.C.; Russell, J.C.; Broome, K.G.; Ryan, G.J.; Dowding, J.E. Conserving New Zealand's Native Fauna: A Review of Tools Being Developed for the Predator Free 2050 Programme. J. Ornithol. 2019, 160, 1-10. [CrossRef]

40. Emami-Khoyi, A.; Hartley, D.A.; Ross, J.G.; Murphy, E.C.; Paterson, A.M.; Cruickshank, R.H.; Else, T.-A. Complete Mitochondrial Genome of the Stoat (Mustela erminea) and New Zealand Fur Seal (Arctocephalus forsteri) and their Significance for Mammalian Phylogeny. Mitochondrial DNA Part A 2016, 27, 4597-4599. [CrossRef]

41. Emami-Khoyi, A.; Parbhu, S.P.; Ross, J.G.; Murphy, E.C.; Bothwell, J.; Monsanto, D.M.; Vuuren, B.J.V.; Teske, P.R.; Paterson, A.M. De Novo Transcriptome Assembly and Annotation of Liver and Brain Tissues of Common Brushtail Possums (Trichosurusvulpecula) in New Zealand: Transcriptome Diversity after Decades of Population Control. Genes 2020, 11, 436. [CrossRef]

42. Shanmuganandam, S.; Hu, Y.; Strive, T.; Schwessinger, B.; Hall, R.N. Uncovering the Microbiome of Invasive Sympatric European Brown Hares and European Rabbits in Australia. BioRxiv 2019, 832477. [CrossRef]

43. Blanchong, J.A.; Robinson, S.J.; Samuel, M.D.; Foster, J.T. Application of Genetics and Genomics to Wildlife Epidemiology. J. Wildl. Manag. 2016, 80, 593-608. [CrossRef]

44. Flecknell, P. Laboratory Animal Anaesthesia; Academic Press: New York NY, USA, 2015.

45. Hall, L.; Clarke, K.; Trim, C. Veterinary Anaesthesia, 10th ed.; Harcourt Publishers Limited: London, UK, 2001; p. 225.

46. Morgan, D.; Scobie, S.; Arthur, D. Evaluation of Zoletil and Other Injectable Anaesthetics for Field Sedation of Brushtail Possums (Trichosurusvulpecula). Anim. Welf. UFAW J. 2012, 21, 457. [CrossRef]

47. Emami-Khoyi, A.; Benmazouz, I.; Ross, J.G.; Boren, L.J.; Murphy, E.C.; Jansen van Vuuren, B.; Teske, P.R.; Paterson, A.M. A Survey of the Oral Cavity Microbiome of New Zealand Fur Seal Pups (Arctocephalus forsteri). Mar. Mamm. Sci. 2019, 36, 334-343. [CrossRef]

48. Lane, D. 16s/23s Rrna Sequencing. In Nucleic Acid Techniques in Bacterial Systematics; Stackebrandt, E., Goodfellow, M., Eds.; John Wiley and Sons: New York, NY, USA, 1991.

49. Forney, L.J.; Gajer, P.; Williams, C.J.; Schneider, G.M.; Koenig, S.S.; McCulle, S.L.; Karlebach, S.; Brotman, R.M.; Davis, C.C.; Ault, K. Comparison of Self-Collected and Physician-Collected Vaginal Swabs for Microbiome Analysis. J. Clin. Microbiol. 2010, 48, 1741-1748. [CrossRef] [PubMed]

50. Bolyen, E.; Rideout, J.R.; Dillon, M.R.; Bokulich, N.A.; Abnet, C.; Al-Ghalith, G.A.; Alexander, H.; Alm, E.J.; Arumugam, M.; Asnicar, F. Qiime 2: Reproducible, Interactive, Scalable, and Extensible Microbiome Data Science. PeerJ 2018, 2167-9843. [CrossRef] 
51. Martin, M. Cutadapt Removes Adapter Sequences from High-Throughput Sequencing Reads. EMBnet J. 2011, 17, 10-12. [CrossRef]

52. Callahan, B.J.; McMurdie, P.J.; Rosen, M.J.; Han, A.W.; Johnson, A.J.A.; Holmes, S.P. Dada2: High-Resolution Sample Inference from Illumina Amplicon Data. Nat. Methods 2016, 13, 581. [CrossRef]

53. DeSantis, T.Z.; Hugenholtz, P.; Larsen, N.; Rojas, M.; Brodie, E.L.; Keller, K.; Huber, T.; Dalevi, D.; Hu, P.; Andersen, G.L. Greengenes, a Chimera-Checked 16s Rrna Gene Database and Workbench Compatible with Arb. Appl. Environ. Microbiol. 2006, 72, 5069-5072. [CrossRef]

54. Letunic, I. Phylot: Phylogenetic Tree Generator. Available online: Phylot.biobyte.de (accessed on 31 May 2019).

55. Letunic, I.; Bork, P. Interactive Tree of Life (iTOL) v3: An Online Tool for the Display and Annotation of Phylogenetic and Other Trees. Nucleic Acids Res. 2016, 44, W242-W245. [CrossRef]

56. Price, M.N.; Dehal, P.S.; Arkin, A.P. Fasttree 2-Approximately Maximum-Likelihood Trees for Large Alignments. PLoS ONE 2010, 5, e9490. [CrossRef]

57. Faith, D.P. Conservation Evaluation and Phylogenetic Diversity. Biol. Conserv. 1992, 61, 1-10. [CrossRef]

58. Pielou, E.C. The Measurement of Diversity in Different Types of Biological Collections. J. Theor. Biol. 1966, 13, 131-144. [CrossRef]

59. Shannon, C.E.; Weaver, W. The Mathematical Theory of Communication; University of Illinois Press: Urbana, IL, USA, 1949; p. 117.

60. Sørensen, T.J. A Method of Establishing Groups of Equal Amplitude in Plant Sociology Based on Similarity of Species Content and Its Application to Analyses of the Vegetation on Danish Commons; Kommission, I., Hos, E., Eds.; Munksgaard: Copenhagen, Denmark, 1948.

61. Lozupone, C.; Knight, R. Unifrac: A New Phylogenetic Method for Comparing Microbial Communities. Appl. Environ. Microbiol. 2005, 71, 8228-8235. [CrossRef] [PubMed]

62. Lozupone, C.A.; Hamady, M.; Kelley, S.T.; Knight, R. Quantitative and Qualitative B Diversity Measures Lead to Different Insights into Factors That Structure Microbial Communities. Appl. Environ. Microbiol. 2007, 73, 1576-1585. [CrossRef] [PubMed]

63. Gower, J.C. Some Distance Properties of Latent Root and Vector Methods Used in Multivariate Analysis. Biometrika 1966, 53, 325-338. [CrossRef]

64. Vázquez-Baeza, Y.; Pirrung, M.; Gonzalez, A.; Knight, R. Emperor: A Tool for Visualizing High-Throughput Microbial Community Data. Gigascience 2013, 2, 16. [CrossRef]

65. Kruskal, W.H.; Wallis, W.A. Use of Ranks in One-Criterion Variance Analysis. J. Am. Stat. Assoc. 1952, 47, 583-621. [CrossRef]

66. Anderson, M.J. Permutational Multivariate Analysis of Variance (Permanova). In Wiley StatsRef: Statistics Reference Online; Wiley Online Library: Hoboken, NJ, USA, 2014; pp. 1-15.

67. Bastian, M.; Heymann, S.; Jacomy, M. Gephi: An Open Source Software for Exploring and Manipulating Networks. In Proceedings of the Third International AAAI Conference on Weblogs and Social Media, San Jose, CA, USA, 17-20 May 2009.

68. Morton, J.T.; Sanders, J.; Quinn, R.A.; McDonald, D.; Gonzalez, A.; Vázquez-Baeza, Y.; Navas-Molina, J.A.; Song, S.J.; Metcalf, J.L.; Hyde, E.R. Balance Trees Reveal Microbial Niche Differentiation. MSystems 2017, 2, e00162-16. [CrossRef]

69. Ward, J.H., Jr. Hierarchical Grouping to Optimize an Objective Function. J. Am. Stat. Assoc. 1963, 58, $236-244$. [CrossRef]

70. Edwards, Y.D.; Allenby, G.M. Multivariate Analysis of Multiple Response Data. J. Mark. Res. 2003, 40, 321-334. [CrossRef]

71. Douglas, G.M.; Maffei, V.J.; Zaneveld, J.; Yurgel, S.N.; Brown, J.R.; Taylor, C.M.; Huttenhower, C.; Langille, M.G. Picrust2: An Improved and Extensible Approach for Metagenome Inference. BioRxiv 2019, 672295.

72. Karp, P.D.; Billington, R.; Caspi, R.; Fulcher, C.A.; Latendresse, M.; Kothari, A.; Keseler, I.M.; Krummenacker, M.; Midford, P.E.; Ong, Q. The Biocyc Collection of Microbial Genomes and Metabolic Pathways. Brief. Bioinform. 2017, 20, 1085-1093. [CrossRef] [PubMed]

73. Dhariwal, A.; Chong, J.; Habib, S.; King, I.L.; Agellon, L.B.; Xia, J. Microbiomeanalyst: A Web-Based Tool for Comprehensive Statistical, Visual and Meta-Analysis of Microbiome Data. Nucleic Acids Res. 2017, 45, W180-W188. [CrossRef] 
74. Gao, L.; Xu, T.; Huang, G.; Jiang, S.; Gu, Y.; Chen, F. Oral Microbiomes: More and More Importance in Oral Cavity and Whole Body. Protein Cell 2018, 9, 488-500. [CrossRef] [PubMed]

75. Adler, C.J.; Malik, R.; Browne, G.V.; Norris, J.M. Diet May Influence the Oral Microbiome Composition in Cats. Microbiome 2016, 4, 23. [CrossRef] [PubMed]

76. Kato, I.; Vasquez, A.; Moyerbrailean, G.; Land, S.; Djuric, Z.; Sun, J.; Lin, H.-S.; Ram, J.L. Nutritional Correlates of Human Oral Microbiome. J. Am. Coll. Nutr. 2017, 36, 88-98. [CrossRef]

77. Gogarten, J.F.; Davies, T.J.; Benjamino, J.; Gogarten, J.P.; Graf, J.; Mielke, A.; Mundry, R.; Nelson, M.C.; Wittig, R.M.; Leendertz, F.H. Factors Influencing Bacterial Microbiome Composition in a Wild Non-Human Primate Community in Taï National Park, Côte D'ivoire. ISME J. 2018, 12, 2559-2574. [CrossRef] [PubMed]

78. Ribeiro, A.A.; Azcarate-Peril, M.A.; Cadenas, M.B.; Butz, N.; Paster, B.J.; Chen, T.; Bair, E.; Arnold, R.R. The Oral Bacterial Microbiome of Occlusal Surfaces in Children and Its Association with Diet and Caries. PLoS ONE 2017, 12, e0180621. [CrossRef] [PubMed]

79. Ruparell, A.; Inui, T.; Staunton, R.; Wallis, C.; Deusch, O.; Holcombe, L.J. The Canine Oral Microbiome: Variation in Bacterial Populations across Different Niches. BMC Microbiol. 2020, 20, 1-13. [CrossRef] [PubMed]

80. Hume, I.D. Digestive Physiology and Nutrition of Marsupials; CUP Archive: New York, NY, USA, 1982.

81. Delafont, V.; Samba-Louaka, A.; Bouchon, D.; Moulin, L.; Héchard, Y. Shedding Light on Microbial Dark Matter: A Tm 6 Bacterium as Natural Endosymbiont of a Free-Living Amoeba. Environ. Microbiol. Rep. 2015, 7, 970-978. [CrossRef]

82. Khan, I.; Azhar, E.I.; Abbas, A.T.; Kumosani, T.; Barbour, E.K.; Raoult, D.; Yasir, M. Metagenomic Analysis of Antibiotic-Induced Changes in Gut Microbiota in a Pregnant Rat Model. Front. Pharmacol. 2016, 7, 104. [CrossRef]

83. Wade, W.G. Has the Use of Molecular Methods for the Characterization of the Human Oral Microbiome Changed Our Understanding of the Role of Bacteria in the Pathogenesis of Periodontal Disease? J. Clin. Periodontol. 2011, 38, 7-16. [CrossRef]

84. Chang, C.-W.; Huang, B.-H.; Lin, S.-M.; Huang, C.-L.; Liao, P.-C. Changes of Diet and Dominant Intestinal Microbes in Farmland Frogs. BMC Microbiol. 2016, 16, 33. [CrossRef]

85. Ulloa, P.C.; Van Der Veen, M.H.; Krom, B.P. Modulation of the Oral Microbiome by the Host to Promote Ecological Balance. Odontology 2019, 107, 437-448. [CrossRef] [PubMed]

86. Pearce, D.S. Physiology and Genetics Shape the Microbiome of a Seabird Species (Oceanodromaleucorhoa) More than Environmental and Social Factors. Master's Thesis, Western Michigan University, Kalamazoo, MI, USA, 2016.

87. Lamont, R.J.; Koo, H.; Hajishengallis, G. The Oral Microbiota: Dynamic Communities and Host Interactions. Nat. Rev. Microbiol. 2018, 16, 745-759. [CrossRef] [PubMed]

88. Compo, N.R.; Gomez, D.E.; Tapscott, B.; Weese, J.S.; Turner, P.V. Fecal Bacterial Microbiota of Canadian Commercial Mink (Neovison vison): Yearly, Life Stage, and Seasonal Comparisons. PLoS ONE 2018, 13, e0207111. [CrossRef] [PubMed]

89. Blekhman, R.; Goodrich, J.K.; Huang, K.; Sun, Q.; Bukowski, R.; Bell, J.T.; Spector, T.D.; Keinan, A.; Ley, R.E.; Gevers, D. Host Genetic Variation Impacts Microbiome Composition across Human Body Sites. Genome Biol. 2015, 16, 191. [CrossRef] [PubMed]

90. Davenport, E.R.; Cusanovich, D.A.; Michelini, K.; Barreiro, L.B.; Ober, C.; Gilad, Y. Genome-Wide Association Studies of the Human Gut Microbiota. PLoS ONE 2015, 10, e0140301. [CrossRef] [PubMed]

91. Folseraas, T.; Melum, E.; Rausch, P.; Juran, B.D.; Ellinghaus, E.; Shiryaev, A.; Laerdahl, J.K.; Ellinghaus, D.; Schramm, C.; Weismüller, T.J. Extended Analysis of a Genome-Wide Association Study in Primary Sclerosing Cholangitis Detects Multiple Novel Risk Loci. J. Hepatol. 2012, 57, 366-375. [CrossRef] [PubMed]

92. Goodrich, J.K.; Davenport, E.R.; Beaumont, M.; Jackson, M.A.; Knight, R.; Ober, C.; Spector, T.D.; Bell, J.T.; Clark, A.G.; Ley, R.E. Genetic Determinants of the Gut Microbiome in UK Twins. Cell Host Microbe 2016, 19, 731-743. [CrossRef] [PubMed]

93. Goodrich, J.K.; Waters, J.L.; Poole, A.C.; Sutter, J.L.; Koren, O.; Blekhman, R.; Beaumont, M.; Van Treuren, W.; Knight, R.; Bell, J.T. Human Genetics Shape the Gut Microbiome. Cell 2014, 159, 789-799. [CrossRef]

94. Knights, D.; Silverberg, M.S.; Weersma, R.K.; Gevers, D.; Dijkstra, G.; Huang, H.; Tyler, A.D.; Van Sommeren, S.; Imhann, F.; Stempak, J.M. Complex Host Genetics Influence the Microbiome in Inflammatory Bowel Disease. Genome Med. 2014, 6, 107. [CrossRef] 
95. Suzuki, T.A.; Phifer-Rixey, M.; Mack, K.L.; Sheehan, M.J.; Lin, D.; Bi, K.; Nachman, M.W. Host Genetic Determinants of the Gut Microbiota of Wild Mice. Mol. Ecol. 2019, 28, 3197-3207. [CrossRef]

96. Awany, D.; Allali, I.; Dalvie, S.; Hemmings, S.; Mwaikono, K.S.; Thomford, N.E.; Gomez, A.; Mulder, N.; Chimusa, E.R. Host and Microbiome Genome-Wide Association Studies: Current State and Challenges. Front. Genet. 2019, 9, 637. [CrossRef]

97. Beilsmith, K.; Thoen, M.P.; Brachi, B.; Gloss, A.D.; Khan, M.H.; Bergelson, J. Genome-Wide Association Studies on the Phyllosphere Microbiome: Embracing Complexity in Host-Microbe Interactions. Plant J. 2019, 97, 164-181. [CrossRef]

98. Lozupone, C.A.; Stombaugh, J.I.; Gordon, J.I.; Jansson, J.K.; Knight, R. Diversity, Stability and Resilience of the Human Gut Microbiota. Nature 2012, 489, 220. [CrossRef]

99. Taxis, T.M.; Wolff, S.; Gregg, S.J.; Minton, N.O.; Zhang, C.; Dai, J.; Schnabel, R.D.; Taylor, J.F.; Kerley, M.S.; Pires, J.C. The Players May Change but the Game Remains: Network Analyses of Ruminal Microbiomes Suggest Taxonomic Differences Mask Functional Similarity. Nucleic Acids Res. 2015, 43, 9600-9612. [CrossRef] [PubMed]

100. Bradley, P.H.; Pollard, K.S. Proteobacteria Explain Significant Functional Variability in the Human Gut Microbiome. Microbiome 2017, 5, 36. [CrossRef] [PubMed]

101. Sharpton, T.J. Role of the Gut Microbiome in Vertebrate Evolution. MSystems 2018, 3, e00174-17. [CrossRef] [PubMed]

102. Camboim, E.K.; Almeida, A.P.; Tadra-Sfeir, M.Z.; Junior, F.G.; Andrade, P.P.; McSweeney, C.S.; Melo, M.A.; Riet-Correa, F. Isolation and Identification of Sodium Fluoroacetate Degrading Bacteria from Caprine Rumen in Brazil. Sci. World J. 2012, 2012, 178254. [CrossRef] [PubMed]

(C) 2020 by the authors. Licensee MDPI, Basel, Switzerland. This article is an open access article distributed under the terms and conditions of the Creative Commons Attribution (CC BY) license (http://creativecommons.org/licenses/by/4.0/). 